\title{
Long-term Results of Endoscopic Balloon Dilatation for Gastric Outlet Obstruction Caused by Peptic Ulcer Disease
}

\author{
Ehsan Zare ${ }^{1}$, Hadi Raeisi ${ }^{2}$, Behnam Honarvar ${ }^{3}$, Kamran B. Lankarani 3,*
}

1. Gastroenterology and Hepatology Research Center, Shiraz University of Medical Sciences, Shiraz, Islamic Republic of Iran

2. Department of Biostatistics, Shahre Kord University of Medical Sciences, Shahrekord, Islamic Republic of Iran

3. Health Policy Research Center, Institute of Health, Shiraz University of Medical Sciences, Shiraz, Islamic Republic of Iran

\footnotetext{
* Corresponding Author:

Kamran B. Lankarani, M.D

Health Policy Research Center, Shiraz

School of Medicine, Zand Blvd, Shiraz,

IR Iran, Postal code: 7134845794

Telefax: + 987132309615

Email: lankaran@sums.ac.ir

Received: 29 May. 2019

Accepted: 02 Sep. 2019
}

\section{ABSTRACT}

\section{BACKGROUND}

Gastric outlet obstructions (GOO) is a disabling complication of peptic ulcer disease (PUD). The introduction of endoscopic through the scope balloon dilatation (EBD) has eased the management but there are few reports on the long term results of this modality of treatment on patients' symptoms.

\section{METHODS}

Over a period of 4 years from January 2012 to December 2015 in two major referral hospitals affiliated to Shiraz university, medical endoscopy reports were reviewed retrospectively to identify those who received EBD for the treatment of GOO due to PUD .All of these patients were recalled and their current status were evaluated.

\section{RESULTS}

22 consecutive patients with symptomatic GOO secondary to benign stricture underwent endoscopic balloon dilatation by a single operator. Of them, 14 had balloon dilatation twice and 6 had ballooning three times. The interval between the first referral and the last follow-up was $25.2 \pm 10.3$ (min: 4.8 max:43.4) months.

The averages of maximum balloon size were $14.4 \pm 5 \mathrm{~mm}$ in the first session, $14.3 \pm 3.1 \mathrm{~mm}$ in the second session, and $16 \pm 2.4 \mathrm{~mm}$ in the third session. $73 \%$ of the patients had a significant improvement in clinical symptom with two sessions of EBD and did not require repeat dilatation.

\section{CONCLUSION}

EBD is a safe and efficient method in the management of GOO with good long term results.

\section{KEYWORDS:}

Duodenal Ulcer, Stomach Ulcer, Gastric Outlet Obstruction, Endoscopy, Helicobacter Pylori

Please cite this paper as:

Zare E, Raeisi H, Honarvar B, B. Lankarani K. Long-term Results of Endoscopic Balloon Dilatation for Gastric Outlet Obstruction Caused by Peptic Ulcer Disease. Middle East $J$ Dig Dis 2019;11:218-224. doi:10.15171/mejdd.2019.152.

\section{INTRODUCTION}

Gastric outlet obstruction (GOO) is known as a clinical and pathophysiological complication of some diseases, which interrupts gastric emptying and is characterized by postprandial fullness, abdominal discomfort, and vomiting due to mechanical obstruction in the outlet of stomach. The entity includes obstructive lesions in the antropyloric area, and the bulbar or post bulbar duodenal segments. 
The term GOO is a misnomer since many cases are not due to isolated gastric pathology, but rather involve duodenal or extraluminal disease.

Though malignancy remains as an important cause of GOO in adults. ${ }^{1,2}$ a significant number of patients with GOO have benign diseases. Among the latter are peptic ulcer disease, caustic ingestion, post-operative anastomotic strictures, and inflammatory causes including Crohn's disease and tuberculosis. Less common causes include chronic pancreatitis, annular pancreas, and non-steroidal anti-inflammatory drug-induced strictures. ${ }^{1,2}$

Despite numerous studies, the incidence of GOO is not exactly clear. It seems that the incidence and prevalence of GOO have declined in recent years due to widespread use of proton pump inhibitors (PPIs). A recent study reported that the incidence of GOO had been less than 5\% in patients with PUD, the leading cause of benign GOO. ${ }^{3}$

The pattern of the disease has changed substantively with the introduction of more effective treatment of acid peptic disease including eradication of Helicobacter pylori (H. pylori) and the use of PPIs. Studies showed that until 1970s, benign diseases were the most common causes of GOO while $10-39 \%$ of GOO was due to malignancy. ${ }^{3-7}$ In contrast, in recent years, $50-80 \%$ of $\mathrm{GOO}$ is due to malignant cause. ${ }^{3}$

The most common clinical symptoms among patients with GOO were epigastric pain (94\%), vomiting (92\%), weight loss (63\%), early satiety (53\%), and bloating (50\%). ${ }^{8}$

Although the diagnosis of GOO may be suspected based on clinical symptoms and physical examination but it should be confirmed by radiological evaluation and/or endoscopy. Upper endoscopy is often needed to exclude malignancy.

In past years the only available treatment for GOO was surgical drainage procedures with variable success rates and many complications. There are concerns about the physiological effects of these procedures, which could result in reducing quality of life. ${ }^{9}$ The introduction of endoscopic through the scope balloon dilation (EBD) has simplified the treatment without the need for surgery. ${ }^{9}$ Although there is risk of perforation in complex strictures, it is considered more physiological treatment with overall less hazards for the patients. ${ }^{9}$

There are few studies on the long term follow up of this treatment for GOO due to PUD. In this study we report our experience with this treatment.

\section{MATERIALS AND METHODS}

Over a period of 4 years from January 2012 to December 2015 in two major referral university-affiliated hospitals in Shiraz (Nemazee and Faghihi hospitals), medical endoscopy reports were reviewed retrospectively to identify those who received EBD for the treatment of GOO due to PUD. The patients were excluded if they had malignancy.

A total of 22 cases were found who received EBD for GOO secondary to PUD. All of them were recalled in 2016-2017 and were evaluated clinically. Their clinical symptoms evolution after EBD were specifically asked using a 5- digit score (the worse was 5) done at least on two sessions of clinical visits by two different interviewer to increase the validity. The questioned symptoms were: nausea, vomiting, reflux, weight loss, and abdominal pain. Their hospital and outpatient files were also reviewed.

\section{Procedure:}

Patients should not receive anything by mouth for at least 12 hours. Endoscopic dilatation was performed under conscious sedation by titrated intravenous opiate and benzodiazepine (midazolam and meperidine). We used through the scope (TTS) balloon (Boston Scientific CRE wire guided, esophageal/pyloric wire guided balloon dilatation catheter, Business \& Technology Park, Cork, IRELAND) sizes between 12-18 mm based on the estimation of the operator. We usually started with $12 \mathrm{~mm}$ and increased the diameter up to $3 \mathrm{~mm}$ in each session. The TTS balloon was positioned across the stricture with endoscopic control over the guide wire inside the balloon. The balloon was distended with air up to 3-4.5 atmosphere according to the manufacturer's instruction and maintained in position for maximum 45 second. The balloon was then deflated and two more dilatations were performed in the same manner in each session. We did not use radiological control. After the procedure we passed the scope to second part of the duodenum to see the post-stricture mucosa (figure 1).

Patients were discharged after 4 hours of observation following the procedure with access to emergency visit if they felt pain or any other discomfort. A control endoscopy was done on one month after EBD. Repeat EBD was done whenever symptoms recurred and/or if strictures were still present in the 1-month follow-up 

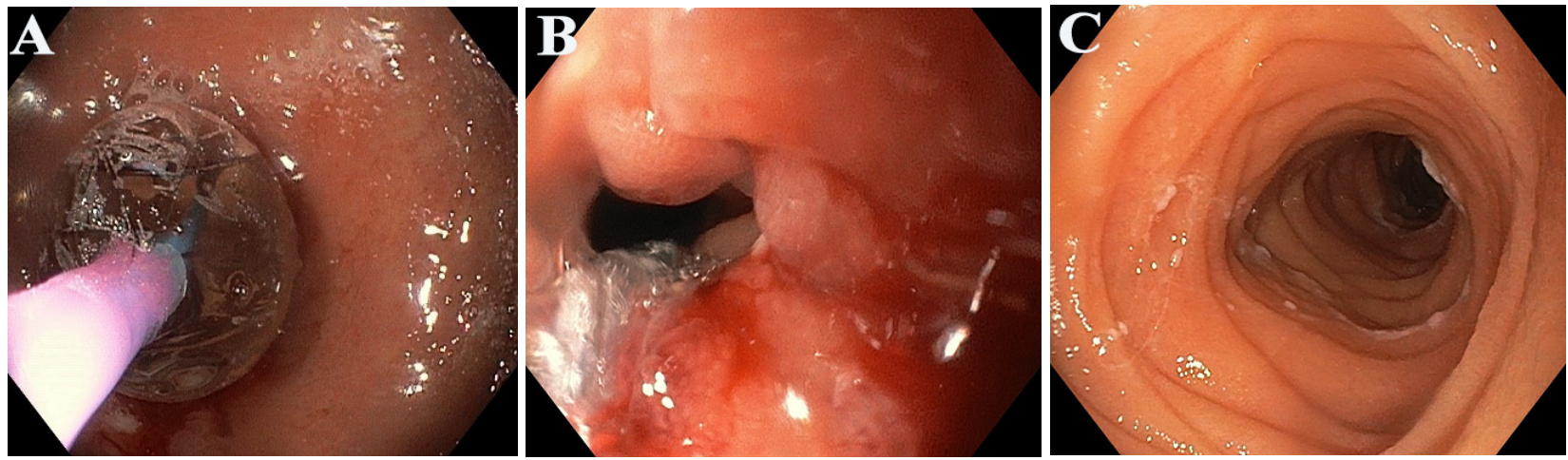

A. Balloon dilation with endoscopic control of pyloric channel

B. The immediate view of pyloric channel after dilation

C. The passage of endoscope to second part of duodenum after dilation for monitoring of possible complication and for evaluation of distal parts

Fig.1: The endoscopic view of the procedure

endoscopy. All patients were treated with PPIs in full therapeutic doses (omeprazole $20 \mathrm{mg}$ twice a day or its equivalent from other PPIs) for 3 months after dilatation. H. pylori infection was investigated in the first endoscopy by taking at least two biopsy samples from the antrum and those with infection received eradication treatment with quadruple therapy (PPI, amoxicillin, Bismuth subcitrate, and metronidazole for the first time treatments and levofloxacin, amoxicillin, and PPI for those who had history of previous eradication treatment). Confirmation of eradication was done with Helicobacter stool Ag assay 1 month after discontinuation of PPI.

Descriptive statistics for categorical and continuous variables were reported as frequency (percent) and median (IQR: Inter quartile range), respectively. To assess the effect of dilatation, score of each symptom was compared before and after the 1st and 2nd and other dilatation using Wilcoxon test. Mann Whitney U test was also used to compare the differences of periods between the 1st, 2nd , and time of interview. All the statistical analyses were performed using SPSS software version 18.0 and level of significant was considered as 0.05 .

\section{RESULTS}

During the 4-year period, 22 patients with GOO due to benign conditions received EBD in these two centers. The mean age of the patients was $56.4 \pm 19.3$ years while most of them were male $(68.2 \%)$ and non-smoker $(72.2 \%)$ (table 1$)$.

None of the patients were alcohol or substance users.
Of the 22 participants, 14 had two sessions of balloon dilatation and 6 cases had ballooning three times. The interval between the first referral and last follow-up was $25.2 \pm 10.3$ (min:4.8, max:43.4) months. The average maximum sizes of the balloons used in the first session were $14.4 \pm 5 \mathrm{~mm}, 14.3 \pm 3.1 \mathrm{~mm}$ in the second, and $16 \pm 2.4 \mathrm{~mm}$ in the third session. $73 \%$ of the patients had a significant improvement in clinical symptom with two sessions of EBD and did not need to receive repeat dilatation. Others had to receive further sessions with maximum of 7 in one patient (table 1).

Table 2 shows the evolution of each symptom after dilation. Figures 2 and 3 and table 3 (in supplement) demonstrate the effect of dilatations on each of the symptoms after dilation and reveal improving of all of the five symptoms naming nausea, vomiting, reflux, weight loss, and abdominal pain after each session of dilation. Median of the total score of patients' symptoms before the first dilation was $21.1 \pm 4.4$ that was significantly decreased to $10.9 \pm 5.2(p<0.001)$ after the first session. Also the median of total score of symptoms before and after the second dilatation were 18.4 and 10.0, respectively. All patients reported improvement after dilation in all sessions. The body mass index of the patients increased from median $19.4 \pm 3.8$ to $22.3 \pm 3.4$ after the first session of balloon dilatation $(p<0.001)$. At the end of treatment and follow-up all patients were comfortable and asymptomatic.

Only three patients had positive histological findings for $H$. pylori and were treated as described above. There was no significant difference between those with active 
Table 1: Patients and procedure characteristics

\begin{tabular}{lc}
\hline Characteristics & Amount $\mathbf{n}$ (\%) \\
\hline Age (year) & $56.4 \pm 19.3$ \\
\hline Mean \pm SD & $60(27-91)$ \\
\hline Median (min-max) & $15(68.2)$ \\
\hline Sex & $7(31.8)$ \\
\hline Male & \\
\hline Female & $9(40.9)$ \\
\hline Smoking & $13(59.1)$ \\
\hline Yes & $2.2 \pm 1.7$ \\
\hline No & $2(1-7)$ \\
\hline Number of gastric ballooning & $14.2 \pm 4.6$ \\
\hline Mean \pm SD & $14.5(6.5-30)$ \\
\hline Median (min-max)
\end{tabular}

Table 2: Evolution of symptoms after balloon dilation

\begin{tabular}{|c|c|c|c|}
\hline \multirow{2}{*}{$\begin{array}{l}\text { Body mass index- Before } \mathbf{1}^{\text {st }} \text { ballooning }\left(\mathbf{k g} / \mathbf{m}^{\mathbf{2}}\right) \\
\text { Mean } \pm \mathrm{SD}\end{array}$} & \multicolumn{3}{|c|}{ Body mass index-After $\mathbf{1}^{\text {st }}$ ballooning $\left(\mathbf{k g} / \mathbf{m}^{2}\right)$} \\
\hline & $19.4 \pm 3.8$ & Mean \pm SD & $22.3 \pm 3.4$ \\
\hline Median (min-max) & $19.7(11.7-28.1)$ & Median (min-max) & $22.6(12.5-26.3)$ \\
\hline Nausea: Before-after $1^{\text {st }}$ Ballooning $(\mathrm{n}=\mathbf{2 2})$ & \multicolumn{3}{|c|}{ Nausea: Before-after $2^{\text {nd }}$ ballooning $(n=14)$} \\
\hline Very severe and intolerable & $7(31.8)-1(4.5)$ & Very severe and intolerable & $3(13.6)-0(0)$ \\
\hline Severe but tolerable & $10(13.6)-1(4.5)$ & Severe but tolerable & $3(13.6)-1(4.5)$ \\
\hline Moderate and very often & $3(13.6)-1(4.5)$ & Moderate and very often & $3(13.6)-1(4.5)$ \\
\hline Moderate and sometimes & $0(0)-5(22.7)$ & Moderate and sometimes & $3(13.6)-1(4.5)$ \\
\hline Weak & $2(9.1)-9(40.9)$ & Weak & $2(9.1)-6(27.3)$ \\
\hline No & $0(0)-5(22.7)$ & No & $0(0)-5(22.7)$ \\
\hline Vomiting: Before-after $1^{\text {st }}$ ballooning $(\mathrm{n}=22)$ & \multicolumn{3}{|c|}{ Vomiting : Before-after $2^{\text {nd }}$ ballooning $(n=14)$} \\
\hline Very severe and intolerable & $8(36.4)-0(0)$ & Very severe and intolerable & $3(13.6)-0(0)$ \\
\hline Severe but tolerable & $4(18.2)-1(4.5)$ & Severe but tolerable & $4(18.2)-1(4.5)$ \\
\hline Moderate and very often & $\begin{array}{c}4(18.2)-2 \\
(9.1)\end{array}$ & Moderate and very often & $2(9.1)-0(0)$ \\
\hline Moderate and sometimes & $4(18.2)-6(27.3)$ & Moderate and sometimes & $1(4.5)-1(4.5)$ \\
\hline Weak & $0(0)-7(31.8)$ & Weak & $2(9.1)-6(27.3)$ \\
\hline No & $2(9.1)-6(27.3)$ & No & $2(9.1)-6(27.3)$ \\
\hline Reflux: Before-after $1^{\text {st }}$ allooning $(\mathrm{n}=\mathbf{2 2})$ & \multicolumn{3}{|c|}{ Reflux: Before-after $2^{\text {nd }}$ ballooning $(\mathrm{n}=14)$} \\
\hline Very severe and intolerable & $2(9.1)-1(4.5)$ & Very severe and intolerable & $1(8.3)-1(4.5)$ \\
\hline Severe but tolerable & $5(22.7)-1(9.1)$ & Severe but tolerable & $1(8.3)-1(4.5)$ \\
\hline Moderate and very often & $4(18.2)-0(0)$ & Moderate and very often & $2(16.7)-0(0)$ \\
\hline Moderate and sometimes & $3(13.6)-4(18.2)$ & Moderate and sometimes & $2(16.7)-2(9.1)$ \\
\hline Weak & $0(0)-3(13.6)$ & Weak & $5(41.7)-4(18.2)$ \\
\hline No & $8(36.4)-12(54.5)$ & No & $1(8.3)-6(27.3)$ \\
\hline
\end{tabular}




\begin{tabular}{lccc}
\hline Weight loss: Before-after 1st ballooning $(\mathbf{n}=\mathbf{2 2})$ & \multicolumn{3}{c}{ Weight loss: Before-after 2nd ballooning $(\mathbf{n}=\mathbf{1 4})$} \\
\hline Very severe and intolerable & $5(22.7)-1(4.5)$ & Very severe and intolerable & $1(8.3)-1(4.5)$ \\
\hline Severe but tolerable & $8(36.4)-1(4.5)$ & Severe but tolerable & $1(8.3)-1(4.5)$ \\
\hline Moderate and very often & $4(18.2)-0(0)$ & Moderate and very often & $2(16.7)-0(0)$ \\
\hline Moderate and sometimes & $1(4.5)-4(18.2)$ & Moderate and sometimes & $4(18.2)-0(0)$ \\
\hline Weak & $3(13.6)-8(36.4)$ & Weak & $5(41.7)-5(22.7)$ \\
\hline No & $1(4.5)-8(36.4)$ & No & $1(8.3)-7(31.8)$ \\
\hline Abdominal pain: Before-after 1st ballooning $(\mathbf{n}=\mathbf{2 2})$ & & Abdominal pain: Before-after 2nd ballooning $(\mathbf{n}=\mathbf{1 4})$ & \\
\hline Very severe and intolerable & $3(13.6)-0(0)$ & Very severe and intolerable & $1(4.5)-0(0)$ \\
\hline Severe but tolerable & $12(54.5)-1(4.5)$ & Severe but tolerable & $5(22.7)-1(4.5)$ \\
\hline Moderate and very often & $2(9.1)-0(0)$ & Moderate and very often & $2(9.1)-0(0)$ \\
\hline Moderate and sometimes & $3(13.6)-5(22.7)$ & Moderate and sometimes & $3(13.6)-2(9.1)$ \\
\hline Weak & $1(4.5)-9(40.9)$ & Weak & $2(9.1)-6(27.3)$ \\
\hline No & $1(4.5)-7(31.8)$ & No & $1(4.5)-5(22.7)$ \\
\hline
\end{tabular}

Table 3: Change of the scores of symptoms before and after ballooning

\begin{tabular}{|c|c|c|c|c|c|c|c|}
\hline \multirow{2}{*}{ Symptom } & \multirow{2}{*}{ Time regarding ballooning } & \multicolumn{3}{|c|}{$\mathrm{D1}^{1}(\mathrm{n}=22)$} & \multicolumn{3}{|c|}{$\mathrm{D}^{2}(\mathrm{n}=14)$} \\
\hline & & Median $^{3}$ & $\mathbf{I Q R}^{4}$ & $p$-value & Median & IQR & $p$ value \\
\hline \multirow{2}{*}{ Nausea } & pre & 5.0 & 1.2 & \multirow{2}{*}{$<0.001$} & 4.0 & 2.2 & \multirow{2}{*}{0.002} \\
\hline & post & 2.0 & 1.2 & & 2.0 & 1.5 & \\
\hline \multirow{2}{*}{ Vomiting } & pre & 5.0 & 3.0 & \multirow{2}{*}{$<0.001$} & 5.0 & 3.0 & \multirow{2}{*}{0.003} \\
\hline & post & 2.0 & 2.0 & & 2.0 & 1.0 & \\
\hline \multirow{2}{*}{ Reflux } & pre & 3.0 & 4.0 & \multirow{2}{*}{0.01} & 4.0 & 3.0 & \multirow{2}{*}{0.02} \\
\hline & post & 1.0 & 2.0 & & 2.0 & 2.0 & \\
\hline \multirow{2}{*}{ Weight Loss } & pre & 5.0 & 1.5 & \multirow{2}{*}{$<0.001$} & 3.0 & 2.0 & \multirow{2}{*}{0.006} \\
\hline & post & 2.0 & 2.0 & & 2.0 & 1.0 & \\
\hline \multirow{2}{*}{ Abdominal pain } & pre & 4.0 & 2.5 & \multirow{2}{*}{$<0.001$} & 0.0 & 3.0 & \multirow{2}{*}{0.002} \\
\hline & post & 2.0 & 2.0 & & 2.0 & 1.0 & \\
\hline \multirow{2}{*}{ Total score } & pre & 23.0 & 7.5 & \multirow{2}{*}{$<0.001$} & 18.0 & 10.5 & \multirow{2}{*}{$<0.001$} \\
\hline & post & 10.0 & 9.5 & & 9.0 & 8.0 & \\
\hline
\end{tabular}

$\mathrm{D}^{1} 1$ : First dilatation; $\mathrm{D}^{2} 2$ : Second dilatation; $\mathrm{IQR}^{3}$ : Interquartile range; Median ${ }^{3}$ : For each of five symptoms was out of 6 and for total score was out of 30

infection with $H$. pylori and non-infected patients regarding the response to dilation. All other 19 patients had history of receiving eradication treatment for $H$. pylori infection in the past based on serology, urea breath test, or histology.

Among the 22 patients, $47 \%$ had stenosis at pyloric channel, $5 \%$ in the bulb of duodenum, and $42 \%$ in $\mathrm{d}^{1}+$ $\mathrm{d}^{2}+$ junction $(p<0.001)$.

There was no complication in this series.

\section{DISCUSSION}

A major cause of benign gastroduodenal obstruction is peptic ulcer disease including gastric and duodenal ulcer. ${ }^{10}$ Although surgery was considered as the main therapeutic intervention in such patients, the long term effects of surgery specially the effects of vagotomy, which is usually a part of the procedure, on the quality of life has been a major concern. Introduction of EBD was a momentum in more physiological management of this complication. ${ }^{10}$

In this study long term follow-up of 22 patients with benign GOO who were treated with balloon dilation is reported. $73 \%$ of the patient with two sessions of EBD dilatation had resolution of their symptoms while the others needed three or more sessions of EBD. 


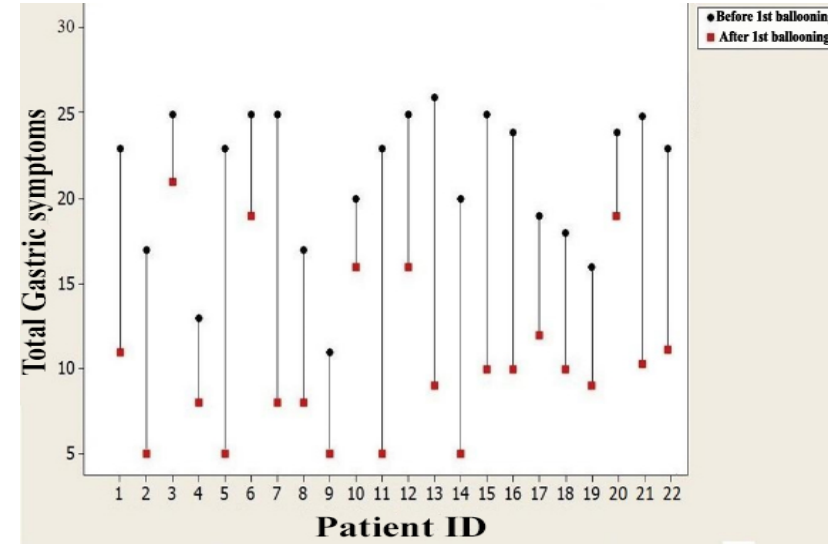

The symptom score was calculated by summation of the self-reported score of five symptoms (Nausea vomiting, reflux, abdominal pain and weight loss) with a five digit score in which 5 was worse.

Fig.2: Evolution of symptom score after the first session of balloon dilation

All the five clinical symptoms improved after intervention. The BMI of the patients was also increased.

In our series, the common site of obstruction was the pylorus, $\mathrm{d}^{1}-\mathrm{d}^{2}$ junction, and bulb of duodenum. No complication including perforation was observed in this study, which might be related to selection bias.

The incidence of GOO is not known precisely. It is likely to have declined in recent years due to decline in PUD, which has been the most cause of GOO in the past. In 1990, as many as 2000 operations for GOO were performed annually only in the United States. ${ }^{3}$ Jaka and colleagues reported that the annual incidence of this complication in developed countries is $1-3$ per 100,000 while in developing countries the estimated annual incidence was higher and up to $4-13$ per $100,000 .{ }^{11}$

The first successful EBD of the pylorus was reported on 1982 by Benjamin and co-workers, ${ }^{12}$ and the technique has been used widely since then with variable modifications. The median number of dilatations per patient ranged from 1.5 to 3 times. ${ }^{13-15} \mathrm{~A}$ single balloon dilatation session was sufficient in $30-67 \%$ of patients in some series. ${ }^{16-17}$ The median balloon diameter was $15 \mathrm{~mm}$ in reported series. ${ }^{18,19}$ In our series, the mean number of sessions of EBD was 2.4. 16 individuals (73\%) had resolution of symptoms after two times ballooning with a median balloon diameter of $14.2 \mathrm{~mm}$. No patient in our series was satisfied with one session of intervention and all needed more than one EBD. This might be related to our more conservative approach or our longer follow-up. The balance between speed and safety should be a major concern when performing EBD. This mandates starting with smaller size of balloons and more conservative



The symptom score was calculated by summation of the self-reported score of five symptoms (Nausea, vomiting, reflux, abdominal pain and weight loss) with a five digit score in which 5 was worse.

Fig.3: Evolution of symptom score after the second session of balloon dilation

approach. ${ }^{20}$ In a recent study on EBD for PUD, the mean number of dilations required was three, which is in concordance to our study. ${ }^{21}$

There are other reports indicating EBD produced short- and medium-term remission and symptom improvement in $65-88 \%$ of patients with an immediate success in $76-100 \%$ of patients. ${ }^{21-24}$ But even in these studies the relapse rate was as high as $39 \%$ with need for surgery in up to $29 \%{ }^{24}$

We used histology to pursue active $H$. pylori infection in our patients. $H$. pylori eradication after EBD has been associated with higher remission rate and less relapse. ${ }^{20,23}$ Our patients with active infection were too few to see any difference. There are also reports of lower success rate of EBD in the presence of smoking and alcohol consumption. ${ }^{20}$ None of our patients were alcohol users and most were non-smokers.

All of the symptoms of the patients in our series except for reflux improved after the first dilation. The earliest improvements were for nausea and abdominal pain after the first dilation followed by weight gain. In the second session nausea, vomiting, and abdominal pain decreased, but there was no clear improvement in the number of reflux and no further weight gain. Our hypothesis about the cause of failure in reflux is the presence of some form of gastric dysmotility in these patients.

This study showed that ballooning dilatation for GOO due to PUD is a safe and efficient method and may eliminate the need for surgery and its related complications in selected patients. Whether these results could be achieved in other etiologies of GOO is a matter of debate. It has been recently shown that strictures due to 
caustic ingestion are more complex with higher rates of non-responsiveness to EBD, higher rates of perforation, and higher number of EBD sessions..$^{20,21}$

This study was in a relatively highly selected patients with no coagulopathy, no severe comorbid disease contraindicating outpatient management, and was done by a single operator with more than two decades of experience in therapeutic endoscopy. These results could not be generalized to all patients and in all centers.

To further establish the benefit of balloon dilatation in patients with benign GOO, controlled and prospective cohort studies with larger numbers of patients might be needed.

\section{REFERENCES}

1. Khullar SK, DiSario JA. Gastric outlet obstruction. Gastrointest Endosc Clin N Am 1996;6:585-603.

2. Johnson CD, Ellis H. Gastric outlet obstruction now predicts malignancy. Br J Surg 1990;77:1023-4. doi: 10.1002/bjs.1800770923.

3. Gibson JB, Behrman SW, Fabian TC, Britt LG. Gastric outlet obstruction resulting from peptic ulcer disease requiring surgical intervention is infrequently associated with Helicobacter pylori infection. J Am Coll Surg 2000; 191:32-7. doi: 10.1016/S1072-7515(00)00298-2.

4. Johnson CD. Gastric outlet obstruction malignant until proved otherwise. Am J Gastroenterol 1995; 90:1740.

5. Kreel L, Ellis H. Pyloric stenosis in adults: A clinical and radiological study of 100 consecutive patients. Gut 1965; 6:253-61. doi: 10.1136/gut.6.3.253.

6. Shone DN, Nikoomanesh P, Smith-Meek MM, Bender JS. Malignancy is the most common cause of gastric outlet obstruction in the era of $\mathrm{H} 2$ blockers. Am J Gastroenterol 1995; 90:1769-70.

7. Chowdhury A, Dhali GK, Banerjee PK. Etiology of gastric outlet obstruction. Am J Gastroenterol 1996; 91:1679.

8. Green ST, Drury JK, McCallion J, Erwin L. Carcinoid tumour presenting as recurrent gastric outlet obstruction: a case of long-term survival. Scott Med J 1987;32:54-5. doi: $10.1177 / 003693308703200212$.

9. Chao HC. Update on Endoscopic management of pediatric gastric outlet obstruction. World J Gastrointest Endosc 2016; 8: 635-45. doi: 10.4253/wjge.v8.i18.635.

10. Kozoll DD, Meyer KA. Obstructing gastroduodenal ulcer, symptoms and signs. Arch Surg 1964;89:491-8. doi: 10.1001/archsurg.1964.01320030081014.

11. Jaka H, Mchembe MD, Rambau PF, Chalya PL. Gastric outlet obstruction at Bugando Medical Centre in Northwestern Tanzania: a prospective review of 184 cases. BMC Surg 2013;13:41. doi: 10.1186/1471-2482-13-41.

12. Benjamin SB, Cattau EL, Glass RL. Balloon dilatation of the pylorus: therapy for gastric outlet obstruction. Gastrointest Endosc 1982;28:253-4. doi: 10.1016/s00165107(82)73105-0.

13. Hewitt PM, Krige JE, Funell IC, Wilson C, Bornman PC. Endoscopic balloon dilatation of peptic pyloroduodenal strictures. J Clin Gastroenterol 1999;28:33-5.

14. Disario JA, Fennerty MB, Tietze CC, Hutson WR, Burt RW. Endoscopic balloon dilation for ulcer induced gastric outlet obstruction. Am J Gastroenterol 1994;89:868-71.

15. Boylan JJ, Gradzka M. Long-term results of endoscopic balloon dilatation for gastric outlet obstruction. Dig Dis Sci 1999;44:1883-6. doi: 10.1023/a:1018807125952.

16. Castro FG, Tanure JC, Coelho LGV. Long-term followup in ulcer patients with gastric outlet obstruction submitted to pneumatic balloon dilatation and Helicobacter pylori eradication. Gastrointest Endosc 2002;55:189-92.

17. Hemphill DJ, Marcon NE, Kortan P, Kandel GP, Siemens M, Haber GB. Predictors of success of endoscopic dilatation of benign gastric outlet obstruction during long-term follow-up. Gastrointest Endosc 1995;41:364. doi: 10.1016/ S0016-5107(05)80312-8.

18. Baneijee S, Cash BD, Dominitz JA, Baron TH, Anderson MA, Ben-Menachem T, et al. The role of endoscopy in the management of patients with peptic ulcer disease. Gastrointest Endeosc 2010;71:663-8. doi: 10.1016/j. gie.2009.11.026.

19. Lau JY, Chung SC, Sung JJ, Chan AC, Ng EK, Suen RC, et al. Through-the-scope balloon dilation for pyloric stenosis: long-term results. Gastrointest Endosc 1996;43:98-101.

20. McNeice A, Tham TC. Endoscopic balloon dilation for benign gastric outlet obstruction: Does etiology matter? Gastrointest Endosc 2018;88:909-11. doi: 10.1016/j. gie.2018.08.007.

21. Kochhar R, Malik S, Gupta P, Reddy YR, Dhaka N, Sinha SK, et al. Etiological spectrum and response to endoscopic balloon dilation in patients with benign gastric outlet obstruction. Gastrointest endosc 2018;88:899-908. doi: 10.1016/j.gie.2018.06.037.

22. Kim JH, Shin JH, Di ZH, Ko GY, Yoon HK, Sung $\mathrm{KB}$, et al. Benign duodenal strictures: treatment by means of fluoroscopically guided balloon dilation. $J$ Vase Interv Radiol 2005;16:543-8. doi: 10.1097/01. RVI.0000150033.13928.D4.

23. Kochhar R, Kochhar S. Endoscopic balloon dilation for benign gastric outlet obstruction in adults. World $J$ Gastrointest Endosc 2010;16 :29-35. doi: 10.4253/wjge. v2.i1.29.

24. Hamzaoui L, Bouassida M, Ben Mansour I, Medhioub M, Ezzine $\mathrm{H}$, Touinsi $\mathrm{H}$, et al. Balloon dilatation in patients with gastric outlet obstruction related to peptic ulcer disease. Arab J Gastroenterol. 2015;16:121-4. doi: 10.1016/j. ajg.2015.07.004 